\title{
Community Perceptions with TB Friendly Readiness during the Covid-19 Period: Lessons Learned from Depok, West Java, Indonesia
}

\author{
Ester Tarida Ulibasa ${ }^{1} \square$ and Ratu Ayu Dewi Sartika ${ }^{2}$ \\ ${ }^{12}$ Faculty of Public Health, University of Indonesia, Indonesia \\ $\square$ Corresponding Author: Ester Tarida Ulibasa, E-mail: estertarida.siahaan@gmail.com
}

\author{
ARTICLE INFORMATION \\ Received: 08 October 2021 \\ Accepted: 14 November 2021 \\ Published: 18 November 2021 \\ Volume: 2 \\ Issue: 2 \\ DOI: $10.32996 /$ jmhs.2021.2.2.12
}

\section{KEYWORDS}

Tuberculosis, prevention, elimination, friendly TBC

\section{ABSTRACT}

Tuberculosis (TB) friendly area will reduce society's stigmatization and increase adherence to treatment for TB patients. The encouragement of the surrounding environment can motivate patients to recover, and it can realize the goals of the SDGs and the Indonesian government to eliminate TB. The government's commitment is needed to build governance in developing TB-friendly areas. The study aimed to Know the community's perception of TB-friendly readiness during the COVID-19 period. The method employed was explanatory research with quantitative method; An online survey was conducted on 230 respondents from the general public from various provinces and 40 TB sufferers in the city of Depok to describe the frequency distribution of respondents' perceptions of knowledge, attitudes, behavior, prevention, and development of TB-friendly villages. The results revealed that Overall (100\%) of the respondents had good knowledge about TB, but attitudes (50.9\%) and behavior (41.3\%) towards TB prevention were still poor. Observations showed that the occupancy of TB patients in densely populated areas still lacked ventilation and lighting. In conclusion, Depok City is not ready for human resources and organizational culture in developing TB-friendly sites. The synergy of communication, coordination, and community involvement is an essential pillar in developing TB-friendly villages. Improved communication, information, and education (IEC) for changes in people's positive attitudes and behavior towards TB prevention.

\section{Introduction}

Tuberculosis is an infectious disease that contributes to the number one death globally and has become a global emergency. The situation is exacerbated by the fact that there are still undetected patients, and TB treatment is not running, impacting drug resistance. 1 The incidence rate of TB in Southeast Asia is 220 per 100,000 population with an incidence rate of drug-resistant TB of 9.2 per 100,000 population and TB treatment coverage of around $73 \%$. The World Health Organization's 2030 target is a $90 \%$ decrease in the number of deaths due to TB, a reduction in the incidence of TB cases by $80 \%$ (new cases per 100,000 population per year), a 35\% decrease in the number of deaths due to TB, and a $20 \%$ decrease in the incidence of TB cases. In 2020 (Global TB Report, 2020). ${ }^{2}$

In 2020, TB sufferers in Indonesia reached $8.5 \%$ of the world's TB patients and positioned Indonesia in the second-highest rank of TB cases after India. It is estimated that there are one in 3 TB cases that have not been touched by the TB program, which is a factor in the difficulty of eliminating TB. Other factors such as poverty, weak political commitment, especially funding, inadequate TB services in health facilities, poor recording and reporting, non-standardized drugs, stigmatization, and discrimination against TB sufferers that still occur in the community are new findings obstacles to eliminating TB. ${ }^{3}$

West Java has the highest number of case notifications compared to other provinces, namely 379/100,000 population. This figure is exacerbated by a decrease in treatment success from $81.15 \%$ (2018) to $77.6 \%$ (2019), away from the national tuberculosis success

Copyright: (C) 2021 the Author(s). This article is an open access article distributed under the terms and conditions of the Creative Commons Attribution (CC-BY) 4.0 license (https://creativecommons.org/licenses/by/4.0/). Published by Al-Kindi Centre for Research and Development, London, United Kingdom. 
achievement of $90 \%$. Considering the number of case notifications and the success of tuberculosis treatment are indicators of TB control, this should be the government's attention. ${ }^{4}$

Depok City is 1 of 27 Cities/Regencies in the West Java region that experienced an increase in TB cases to 171/100,000 from $161 / 100,000$ population in 2018. In 2020, the Depok City Health Service stated that TB cases totaled 2746. This means that the number of TB cases decreased compared to 2019, which amounted to 4965 topics towards the end of the year. This finding follows the results of the 2020 report regarding the discovery of suspected TB cases following the Minimum Service Standards (SPM) of only $18.03 \%$ and the discovery of all TB cases only $42.09 \%$, very far from the achievement of the MSS indicator, which is $100 \%$. Data accompany the report results on the success of TB treatment in Depok City from 2020 to November, which only reached $82.10 \%$, lower than the indicator of treatment success, which was $90 \%$.

The success of treatment is influenced by adherence to taking medication. TB patients will obey when they know well, following the theory that knowledge affects behavior. ${ }^{5}$ Good knowledge about TB needs to be owned by the community considering the stigma on TB sufferers occurs in an environment that does not understand how the transmission process, causes, and prevention of TB is. This stigmatization and discrimination became more complex during the Covid-19 pandemic, and not a few people thought that being exposed to TB would be exposed to Covid-19. A study of 190 respondents stated there were $55.8 \%$ or a total of 106 people who have the stigma of TB.6

Regarding stigmatization, three things often occur discrimination, prejudice, and stereotypes. When stigma is formed and spread in the social environment, it will affect the health behavior of TB sufferers. Therefore, the community must have the correct information about TB and an environment and culture that encourages positive knowledge, attitudes, and behaviors of TB sufferers. Stigma arises from the lack of understanding from a group of people who spread to the environment, so it is essential to understand and deal with the stigma with the contribution of stakeholders such as TB program implementers or policymakers, even related stakeholders. ${ }^{7}$ The results of the study in Ghana state that a positive perspective built by stakeholders will become an opportunity and reduce the threats that arise among TB patients so that they can create a policy and improve TB programs. ${ }^{8}$

Therefore, this study aims to analyze public perceptions of the readiness of the city of Depok in developing TB-friendly village governance from various aspects.

\section{Methodology}

The method used is a quantitative research method that uses a descriptive quantitative analysis approach. The quantitative process was carried out by using an online survey using Google forms to measure knowledge, attitudes, and behavior, with a total of 52 items $(24+28)$ statements in the questionnaire for 230 respondents from the general public spread throughout Indonesia and 40 TB patients in the city of Depok. Quantitative analysis was carried out to describe all respondents' frequency distribution of answers.

\section{Results and Discussion \\ 4.1 Results}

\subsubsection{Quantitative Data Analysis}

The results of the online questionnaire research of the general public obtained 230 respondents Most of them were from West Java (40\%), age the highest was in the age range of 25-35 (44.75\%), the most recent education was bachelor degree (37.4\%). Most of the occupations were private employees (33\%).

\section{A. Distribution of Characteristics of Respondents (Society)}

Table 1.1 Characteristics of Respondents

\begin{tabular}{lll} 
Variable & $\mathbf{N}$ & \% \\
\hline Age & & \\
$14-24$ & 36 & 15.7 \\
$25-35$ & 103 & 44.7 \\
$36-46$ & 57 & 24.8 \\
$47-57$ & 31 & 13.5 \\
$58-69$ & 3 & 1.3 \\
\hline TOTAL & $\mathbf{2 3 0}$ & $\mathbf{1 0 0}$ \\
\hline Last Education & & \\
SMP & 2 & 0.9 \\
SMA/SMK & 34 & 14.8 \\
D1 & 2 & 0.9 \\
\hline
\end{tabular}




\begin{tabular}{|c|c|c|}
\hline D3 & 61 & 26.5 \\
\hline D4 & 10 & 4.3 \\
\hline S1 & 86 & 37.4 \\
\hline S2 & 35 & 15.2 \\
\hline TOTAL & 230 & 100.0 \\
\hline \multicolumn{3}{|l|}{ Domicile } \\
\hline Bali & 4 & 1.7 \\
\hline Banten & 60 & 26.1 \\
\hline DKI Jakarta & 36 & 15.7 \\
\hline West Java & 92 & 40 \\
\hline Central Java & 4 & 1.7 \\
\hline East Java & 1 & 0.4 \\
\hline Central Kalimantan & 1 & 0.4 \\
\hline Lampung & 4 & 1.7 \\
\hline Maluku & 3 & 1.3 \\
\hline NTB & 12 & 5.2 \\
\hline NTT & 2 & 0.9 \\
\hline South Sulawesi & 3 & 1.3 \\
\hline North Sulawesi & 2 & 0.9 \\
\hline Sumatera Barat & 1 & 0.4 \\
\hline North Sumatra & 2 & 0,9 \\
\hline Yogyakarta & 3 & 1.3 \\
\hline TOTAL & 230 & 100 \\
\hline \multicolumn{3}{|l|}{ Employment } \\
\hline Not / Not Working & 2 & 0.9 \\
\hline IRT & 20 & 8.8 \\
\hline Student / Students & 17 & 7.4 \\
\hline Teacher / Lecturer & 8 & 3.5 \\
\hline Private Employees Workers & 76 & 33 \\
\hline Retired ASN & 3 & 1.4 \\
\hline PNS/ASN/BUMN & 38 & 16.6 \\
\hline Health & 47 & 20 \\
\hline Self Employed & 11 & 4.9 \\
\hline Freelance & 5 & 2.2 \\
\hline Honorary & 3 & 1.3 \\
\hline TOTAL & 230 & 100.0 \\
\hline
\end{tabular}

The highest proportion of age $25-35$ is $44.7 \%$, the most increased education is bachelor degree $37.4 \%$ most domicile in West Java $40 \%$. The highest proportion of work as private employees is 76 people $33 \%$, and respondents do not work two people $(0.9 \%)$

4.2 Description of Knowledge, Attitudes, and Behavior of Respondents (Society)

Table 1.2 Description of Knowledge, Attitudes, and Behavior of Respondents

\begin{tabular}{|l|l|l|}
\hline Variable & Amount (n) & Percentage (\%) \\
\hline Knowledge & 0 & 0 \\
\hline Lack of & 0 & 0 \\
\hline Enough & 230 & 100 \\
\hline Good & 230 & 100 \\
\hline TOTAL & \multicolumn{2}{|l|}{} \\
\hline Attitude & 113 & 49.1 \\
\hline Good &
\end{tabular}




\begin{tabular}{|l|l|l|}
\hline Bad & 117 & 50.9 \\
\hline TOTAL & 230 & 100 \\
\hline Behavior & 113 & 58.7 \\
\hline Good & 117 & 41.3 \\
\hline Bad & 230 & 100 \\
\hline TOTAL & \multicolumn{2}{|l|}{} \\
\hline
\end{tabular}

Well behaved $58.7 \%$ ), there are $41.3 \%$ of people who misbehave. $100 \%$ of the people have good knowledge about TB. $49.1 \%$ good attitudes and 117 bad attitudes (50.9\%).

4.3 Distribution of Respondents Characteristics (TB Patients)

Table 1.3 Description of Respondent Characteristics

\begin{tabular}{|c|c|c|}
\hline Variable & Amount (n) & $\%$ \\
\hline \multicolumn{3}{|l|}{ Age } \\
\hline $14-24$ & 9 & 22.5 \\
\hline $25-35$ & 12 & 30 \\
\hline $36-46$ & 8 & 20 \\
\hline $47-57$ & 5 & 12.5 \\
\hline $58-69$ & 6 & 15 \\
\hline TOTAL & 40 & 100 \\
\hline \multicolumn{3}{|l|}{ Last Education } \\
\hline Elementary School & 2 & 5 \\
\hline Junior & 4 & 10 \\
\hline SMA / SMK & 29 & 72.5 \\
\hline D3 & 2 & 5 \\
\hline S1 & 3 & 7.5 \\
\hline TOTAL & 40 & 100 \\
\hline \multicolumn{3}{|l|}{ Employment } \\
\hline Not / Not Working & 5 & 12.5 \\
\hline IRT & 15 & 37.5 \\
\hline Student / Student & 3 & 7.5 \\
\hline Teacher / Lecturer & 1 & 2.5 \\
\hline Private Employees & 11 & 27.5 \\
\hline Freelance & 1 & 2.5 \\
\hline Labor & 4 & 10 \\
\hline TOTAL & 40 & 100 First \\
\hline \multicolumn{3}{|l|}{ Treatment } \\
\hline (1) & 3 & 7.5 \\
\hline Two (2) & 8 & 20 \\
\hline Three (3) & 7 & 17.5 \\
\hline Four (4) & 3 & 7.5 \\
\hline Five (5) & 5 & 12.5 \\
\hline $\operatorname{Six}(6)$ & 7 & 17.5 \\
\hline$>6$ & 7 & 17.5 \\
\hline TOTAL & 40 & 100 \\
\hline \multicolumn{3}{|c|}{ TB Experience Previous } \\
\hline Yes & 19 & 47.5 \\
\hline No & 21 & 52.5 \\
\hline TOTAL & 40 & 100 \\
\hline
\end{tabular}


$30 \%$ of respondents are aged 25-35 years, the highest level of education is SMA SMK $72 \%$. Most occupations are housewives, $37.5 \%$. Most of the 2 nd TB treatment respondents were $20 \%$, as many as $47.5 \%$ respondents had a previous TB history, and $52 \%$ had been exposed to TB.

\subsection{Description of Knowledge, Attitudes, and Behavior of TB Respondents}

Table 1.4 Description of Knowledge, Attitudes, and Behavior of TB Respondents

\begin{tabular}{|l|l|l|}
\hline \multicolumn{2}{|l|}{ Variable } & \multicolumn{2}{l|}{ Percentage (\%) } \\
\hline Knowledge & 0 & 0 \\
\hline Lack of & 0 & 0 \\
\hline Enough & 0 & 100 \\
\hline Good & 40 & 100 \\
\hline TOTAL & 40 & \\
\hline Attitude & \multicolumn{2}{|l|}{} \\
\hline Good & 20 & 50 \\
\hline Bad & 20 & 50 \\
\hline TOTAL & 20 & 100 \\
\hline Behavior & 40 & 500 \\
\hline Good & \multicolumn{2}{|l|}{} \\
\hline Bad & \multicolumn{2}{|l|}{} \\
\hline
\end{tabular}

$100 \%$ of TB patients have good knowledge. $50 \%$ of TB sufferers have good attitudes, and $50 \%$ have bad attitudes. There are still $50 \%$ of TB patients who are misbehaving.

TB patients most aged $14-24$ years is $33.3 \%$, with an education past high school / vocational $79.1 \%$, worked as a housewife (37.5\%), in the treatment in the 2nd and 6th (20.8\%), and 62.5\% of TB patients had had TB before. (Table 4). TB patient 100\% good knowledge, attitude both $45.8 \%$ and poor $54.2 \%$ against tuberculosis, as well as well-behaved $54.2 \%$ and poor $45.8 \%$ of the cases of tuberculosis (Table 5)

\section{Discussions}

The problem of TB has become a global problem and a complex one that can not be addressed by the organization independent 10 (Emerson and Nabatchi, 2015). It takes the readiness of various arrangements, both individuals and groups, as an organization (Saragih, 2015). One of the factors that influence organizational readiness is government commitment. This study shows that Depok city stakeholders have not synergized to eradicate TB through policies or regulations to help TB sufferers. Therefore, needed, collaboration governance is primarily during the Covid-19 pandemic. Collaboration governance can be carried out in the development and decision-making with concepts at the organizational level and academics, entrepreneurs, media, and communities (Ansell and Gash, 2007). ${ }^{11}$ Utilization of this model is expected to increase a sense of togetherness and become a form of intelligent use of power as the implementation of culture and local wisdom through skills, systems, and structures to achieve the target, namely community welfare (Baihaki et al., 2020). 
The development of TB-friendly areas requires the readiness of infrastructure aspects, facilities, and infrastructure to prevent and treat TB. In this study, the informant stated that the infrastructure aspect of the TB program at the health facility level was still hampered. The crowded environment and housing for TB sufferers and lack of lighting make it difficult for TB patients to recover. Infrastructure is not a fixed or closed but dynamic system that develops according to the policies or needs of an organization 12. As the case at the health Center Bara Baraya, difficulties in accessing homes patients' are low levels of education, awareness of treatment, and lack of family care for the TB treatment process cause complex problems in the treatment process for TB patients. The government is thinking of alternatives to reach out with MoRoTI (Motor Ramah Orang dengan Tuberkulosis) which aims to mobilize preventive and promotive activities across sectors. Dewi's research, 2020 confirms the importance of this commitment related to infrastructure. Because molecular rapid test kits (TCM) are still limited in the city of Depok, to overcome the problem of drug-resistant TB through the use and access of TCM tools, it is necessary to improve the specimen delivery system, appropriate records, and reports. Policies and establish a referral network for utilization ${ }^{23}$ (Dewi, 2018).

This section is a comparative or descriptive analysis based on the study results, previous literature, etc. The results should be offered in a logical sequence, given the most important findings first and addressing the stated objectives. The author should deal only with new or essential aspects of the results obtained. It should address the relevance of the findings in the context of existing literature or contemporary practice.

\subsection{Limitations}

During the pandemic, the city of Depok is often included in the red zone area, so the data collection process is carried out online for both quantitative and qualitative. It made observations, but very limited, to see how the TB service process and the environmental situation of TB patients were.

\section{Conclusion}

Public perception is characterized by the presence of patients who misbehave, of course, there is still a need for readiness in aspects of human resources, communication, information, and education (KIE). To change attitudes and positive behavior of the community towards TB prevention, but still not ready for inter-agency coordination and communication which causes various efforts to eliminate TB to be not optimal. Therefore, the determination of regional leadership policies as a legal basis, the role of academics in carrying out the tri dharma of higher education, community/cadres in providing information media about TB, as well as advocacy by looking at the presence of the public in conveying information related to TB problems in collaboration with the private sector in providing advertisements. TB services aim to build good governance in implementing TB-friendly villages in Depok City.

Funding: This study was supported by PUTI Grant from Indonesia University with contract number NKB5/UN2.ERST/HKP.05.00/2020)

Acknowledgments: We would like to thank the Depok City Health Office and PUSKESMAS in Depok City, who contributed to this study.

Conflicts of Interest: The authors report no conflict of interest.

\section{References}

[1] Agustin, I and Irma P. (2012). Determinants of Category Two Tuberculosis Treatment Failure in Pulmonary Tuberculosis Patients at Jember Pulmonary Hospital. The Indonesian Journal of Health Science, 2.

[2] Akadun. (2007). Good Governance in Regional Autonomy. Sosiohumanities: Journal of Social Sciences and Humanities, 9, $37-47$.

[3] Al-Rasheed, M. (2020). No Protective Behavior against COVID-19 among the Public in Kuwait: An Examination of the Protection Motivation Theory, Trust in Government, and sociodemographic FactorsTile. Social Work in PublicHealth, 35:7, 546-. https://doi.org//19371918.2020.1806171

[4] Amo-Adjei, J. (2013). Perspectives of Stakeholders on the Sustainability of Tuberculosis Control Program in Ghana Tuberculosis Research and Treatment, 2013, 1-6. https://doi.org/10.1155/2013/419385

[5] Ansell, C., \& Gash, A. (2007). Collaborative governance in theory and practice Journal of Public Administration Research and Theory, 18(4). https://doi.org/10.1093/jopart/mum032

[6] Avelino, G, Lorena, G, \& Biderman, C. (2014). Governance in Managing Public Health Resources in Brazilian Municipalities. Health Policy and Planning, 694-702.

[7] Ayuningtyas, D. (2018). Health Policy Analysis: Principles and Applications.

[8] Bresenham, D., Kipp, AM, \& Medina-Marino, A. (2020). Quantification and correlates of tuberculosis stigma along the tuberculosis testing and treatment cascades in South Africa: a cross-sectional study. Infectious Diseases of Poverty, 9(1), 1-13. https://doi.org/10.1186/s40249020-00762-8

[9] Daniel GD, Degi, J., \& Pedro, S. (2020). Stigma matters in ending tuberculosis: Nationwide survey of stigma in Ethiopia. BMC Public Health, 20:190. 
[10] Dewi, PA (2020). Evaluation of the use of molecular rapid test kits (TCM) in the discovery of drug-resistant TB cases at the health Center, Pancoran Mas District Depok in 2020. The University of Indonesia.

[11] West Java Health Office. (2019). West Java Health Profile.

[12] Emerson, K., and NT (2015). Collaborative Governance Regimes (BA Radin (ed.)). Georgetown University Press. http://press.georgetown.edu/book/georgetown/collaborative-governance-regimes

[13] Hotnaidah S, E. (2015). Individual Attributes of Change Readiness: A Case Study at Indonesia State-owned Railway Company. Procedia Social and Behavioral Sciences, 172, 34-41. https://doi.org/https://doi.org/10.1016/j.sbspro.2015.01.332

[14] https://tuxedovation.inovasi.litbang.kemendagri.go.id/detail_inovasi/14061 28 Feb 2021. (2021).

[15] Idris, K. . M. (2017). Depok Mayor Regulation No. 10 of 2017 concerning Guidelines for Child-Friendly Cities. http://jdih.depok.go.id/assets/uploads/files/product/perwal no 10 of 2017 guidelines for developing child-friendly cities.pdf

[16] Kamaluddin, S. (2019). Good Governance at the Okhika District Office, Gunung Bintang Regency. Journal of Administration and Government Science Vol 3, (1): 222-28.

[17] Lau, Lincoln LH, Hung, N, Dodd, W, Lim, K, Ferma, J. D, and Cole, D.C (2020). Social Trust and Health Seeking Behaviors: A Longitudinal Study of A Community-based Active Tuberculosis Case Finding Program in the Philippines. SSM Popul Health., 12. https://doi.org/10.1016/j.ssmph.2020.100664

[18] Li, X., Wang, B., Tan, D., Li, M., Zhang, D., Tang, C., Cai, X., Yan, Y., Zhang, S., Jin, B., Yu, S., Liang, X., Chu, Q., \& Xu, Y. (2018). Effectiveness of comprehensive social support interventions among elderly patients with tuberculosis in communities in China: a community-based trial. Journal of Epidemiology and Community Health, 72(5). https://doi.org/10.1136/jech-2017-209458

[19] ME T. (2018). Analysis of the Management of the Pulmonary TB Control Program with the DOTS Strategy at the Belawan Public Health Center, Medan Belawan District. The University of Northern Sumatra.

[20] Manalu, HS (2010). Factors Affecting the Incidence of Pulmonary TB and its Management Efforts. Journal of Health Ecology, Vol.9 No 4 , $1340-1346$

[21] Niarta, W., Supardi, S. (2004). Evaluation of the impact of the management intervention of the tuberculosis eradication program by World Vision Indonesia (WVI) in North Central Timor Regency. Health Science. 2004; 17(3): 98-104.

[22] Pranita, E. (2020, January). Ridwan Kamil: Elimination of TB in 2030 is a big challenge in West Java. https://sains.kompas.com/read/2020/01/30/125000923/ridwan-kamil-elimination-tbc-2030-jadi-tantangan-besar-di-jawabarat?page $=$ all\%0D

[23] Pratiwi, N, L. (2012). Community Independence in Transmission Prevention Behavior. Health System Research Bulletin, Vol.15 no., $162-169$.

[24] Personal, T, Novi, M. (2017). Community Knowledge with Stigmatization of Pulmonary TB Patients in the Work Area of Karang Anyar Health Center, South Lampung Regency. Journal of Health, Vol 11, 265-270.

[25] Ridwan, M. (2014). The relationship between the level of knowledge and attitudes with the behavior of preventing tuberculosis transmission in the working area of the Ngemplak Public Health Center, Boyolali district. Muhammadiyah Surakarta university.

[26] Rifkin, SB (2014). Examining the links between community participation and health outcomes: a review of the literature. Oxford Journals Health Policy Planning, 29(Suppl 2, 98-106. https://doi.org/10.1093/heapol/czu076

[27] Wiwit, Z, B. (2013). Evaluation of Pulmonary Tuberculosis Countermeasure in Boyolali DistrictNo Title. Jurnal Kesehatannational,

[28] World Health Organization. (2019). Global TB report.

[29] Yu, WY, Lu, PX, \& Tan, WG (2019). tuberculosis control in migrating population. in tuberculosis Control in MigratingPopulation.https://doi.org $/ 10.1007 / 978-981-32-9763-0$ 